Sunday Grève, Sebastian. 2015. "The Importance of Understanding Each Other in Philosophy.” Philosophy 90: 213-39. https://doi.org/10.1017/S0031819115000 $\underline{029}$

※ Pre-print version (but identical with the published version): page numbers corresponding to the published version appear in the form of [p. ].

\title{
The Importance of Understanding Each Other in Philosophy
}

Sebastian Sunday Grève

\begin{abstract}
What is philosophy? How is it possible? This essay constitutes an attempt to contribute to a better understanding of what might be a good answer to either of these questions by reflecting on one particular characteristic of philosophy, specifically as it presents itself in the philosophical practice of Socrates, Plato and Wittgenstein. Throughout this essay, I conduct the systematic discussion of my topic in parallel lines with the historico-methodological comparison of my three main authors. First, I describe a certain neglected aspect of the Socratic method. Then, exploring the flipside of this aspect, I show that despite the fact that both Socrates and Wittgenstein understand their philosophical approaches as being essentially directed at the particular problems and modes of understanding that are unique to single individuals, they nevertheless aspire to philosophical understanding of the more 'mundane' kind that is directed at the world. Finally, interpreting parts of Plato's dialogues Phaedrus and Laches, I further develop my case for seeing the role of mutual understanding in philosophy as fundamentally twofold, being directed both at the individual and what they say (the word), and at things that are 'external' to this human relation at any particular moment of philosophical understanding (the world).
\end{abstract}

The topics of the modern, of the philosophy of philosophy, and of the form of philosophical writing, come together in the question: What is the audience of philosophy? For the answer to this question will contribute to the answer to the questions: What is philosophy? How is it to be written? In case a philosopher pretends indifference to this question, or not recognize that he has an answer to it, I should note that this question intersects the question: 
What is the teaching of philosophy? Not, of course, that this question is likely to seem more attractive to those responsible for teaching it. ${ }^{1}$ [p. 214]

\section{One aspect of the Socratic method}

What is justice? What is friendship? What is good? What is knowledge? What is philosophy? Socrates typically elicits from his interlocutor an attempt to express their understanding of whatever is at issue in the form of a definition, and proceeds to demonstrate how this definition would yield a series of misunderstandings (or contradictions, according to the standard definition of the elenchus). In the following description of Socrates' methods I focus on a particular aspect of it which, it seems to me, is usually not considered to be of any real importance for its understanding. ${ }^{2}$

A standard account of the Socratic method would usually focus on what we have learnt to understand by the elenchus. ${ }^{3}$ Gregory Vlastos' account has become standard in many ways: 'Socratic elenchus is a search for moral truth by question-and-answer adversary argument in which a thesis is debated only if asserted as the answerer's own belief and is regarded as refuted only if its negation is deduced from his own beliefs'. ${ }^{4}$ It is important, as Socrates repeatedly points out, that the answerer gives short answers (e.g. Gorgias Ip. 215] 449c). This is in order, it is often stressed, that the questioner can stay in control and lead the direction of the search and examination.

1 Stanley Cavell, Must We Mean What We Say? A Book of Essays (Cambridge: Cambridge University Press, 1969/1976), xxiii.

2 I do not claim the Socrates presented in this essay to be closer to the historical Socrates than any other presentation of 'Socrates'. However, saving myself (and you) the hassle of using some sort of index to mark the textual conditions of $m y$ Socrates and equally - given the sheer number of such pretensions on offer in the literature - not seeing a good reason to make those who do not read this footnote not believe that the following is supposed to give a true account of the historical Socrates' methods, I shall continue to call my Socrates simply 'Socrates'.

For reasons of accuracy, however, I should note that the examples of Socrates' philosophical practice that I discuss are all drawn from Plato's 'Socratic dialogues' where there is general agreement concerning Plato's authorship, viz. Apology, Charmides, Crito, Euthydemus, Euthyphro, Gorgias, Ion, Laches, Lesser Hippias, Lysis, Menexenus and Protagoras (following John Cooper's classification, according to which "the term ["Socratic dialogue"] is understood to make no chronological claims, but rather simply to indicate certain broad thematic affinities ... characteristic of the historical Socrates' own philosophical conversations' (Introduction to Plato. Complete Works, edited by John M. Cooper (associate editor D. S. Hutchinson) (Indianapolis: Hackett, 1997), xv)).

3 'First and foremost elenchus is search....its object is always that positive outreach for truth which is expressed by words for searching..., inquiring..., investigating' (Gregory Vlastos, 'The Socratic elenchus: method is all', in Gregory Vlastos, Socratic Studies, edited by Myles Burnyeat (Cambridge: Cambridge University Press, 1994), 4).

4 Ibid. 
The aspect of Socrates' method that I want to focus on instead has to do with a certain tendency of Socrates to focus his philosophical efforts on particular individuals' concerns, as echoed in the second half of Vlastos' short description, 'a thesis is debated only if asserted as the answerer's own belief and is regarded as refuted only if its negation is deduced from his own beliefs'. The way in which Socrates leads his interlocutors to a better understanding and richer appreciation of the complex realities of the thing in question usually involves directly addressing their individual, personal knowledge, beliefs, preconceptions, etc. (so that, in this sense, the one who leads the conversation is actually the answerer, not the questioner).

In most of Plato's Socratic dialogues, Socrates leisurely walks up to a person or a group of people, then something catches his interest and philosophical discourse unfolds. Socrates does not discriminate according to any supposed intellectual expertise, but welcomes conversation with 'anyone I happen to meet, young and old, citizen and stranger'5 (Apology 30a; see also Apology 29d). ${ }^{6}$ Socrates is moved by the daily, mundane themes of his fellow citizens. And he digs into philosophical mud which his interlocutors had not realised they were already half-sunk into, discovering together with them the intricate depths of their unexamined beliefs and related prejudices (namely in some cases, significantly - both those of his interlocutors and those of himself (Socrates) ${ }^{7}$ ).

For example, it can be argued that Socrates' primary interest in his discussion with Euthyphro, whom Socrates happens to meet on his way to court, is not the general concept 'piety' (contra Peter Geach, for example ${ }^{8}$ ), nor to prove or disprove the Delphic oracle (contra Hugh Benson, for example ${ }^{9}$ ), but Euthyphro's legal case against his own father and how Euthyphro ought to act under such extraordinary circumstances. As the conversation develops, it appears to Socrates that Euthyphro is suffering from serious misconceptions concerning notions such as 'piety' and 'justice', and that these misconceptions [p. 216] stand in the way of Euthyphro's seeing clearly relevant implications of his legal case. Hence, Socrates challenges Euthyphro to re-examine some of

5 All translations of Platonic dialogues are cited after Plato. Complete Works, op. cit. note 2.

6 See, for example, the Charmides, Lysis and Menexenus.

7 See, for example, the ending of the Laches; see also Apology 28a.

$8 \quad$ P. T. Geach, 'Plato's Euthyphro', The Monist 50 (3) (1966), 369-82.

9 Hugh Benson, 'Socratic Method', in The Cambridge Companion to Socrates, edited by Donald R. Morrison (Cambridge: Cambridge University Press, 2011). 
his preconceived ideas - successfully, until Euthyphro escapes the continued self-examination ('like Proteus'?), excusing himself ('I am in a hurry now') just when Socrates summarises, 'So we must investigate again from the beginning what piety is'. And it is certainly possible, or this might be Plato's suggestion, that Euthyphro has just had enough of Socrates' midwifery, and thus hurries back into court to retract the charges which he had brought against his own father just before he met Socrates, finding truth in Socrates' concluding words: 'If you had no clear knowledge of piety and impiety you would never have ventured to prosecute your old father for murder on behalf of a servant. For fear of the gods you would have been afraid to take the risk lest you should not be acting rightly, and would have been ashamed before men' (15d-e). When read in this way, the dialogue can actually be seen not to end abruptly (as is often said), nor simply in aporia, ${ }^{10}$ but as marking the appropriate end as achieved by Socrates in successfully moving Euthyphro's practical reason.

\section{Some types of overlooked instances of this aspect}

I want to briefly introduce a number of typical moments in Plato's Socratic dialogues that are apt to further reveal Socrates' striking concern with his individual interlocutors, but which, alas, are often overlooked by readers.

a. There is Socrates' honest interest in the current topic of discussion or whatever is occupying the minds of his respective interlocutors when they meet Socrates. Socrates does not force onto them whatever might be on his mind. 11

b. Socrates takes each of his interlocutors seriously as a person. He makes this explicit in the Gorgias, when he distinguishes his philosophy from oratorical practice, like that of Polus for instance [p. 217] (Socrates' interlocutor in the relevant part of the Gorgias). Socrates is exclusively concerned with his actual interlocutor and only them during their conversation. As he points out to Polus:

SOCRATES: ... I'm only one person, I don't agree with you. You don't compel me; instead you produce many false witnesses against me and

10 See, for example, Cooper's presentation of the standard reading: 'just when [Socrates] is ready to press further to help Euthyphro express his knowledge, if indeed he does possess it, Euthyphro begs off on the excuse of business elsewhere' (Introductory note to the Euthyphro in Plato. Complete Works, op. cit. note 2, 1).

11 See, for example, Euthyphro 3d-4c; Crito 43c-d, 44c, 45a; Laches 181d; Lesser Hippias 363a-b. 
try to banish me from my property, the truth. For my part, if I don't produce you as a single witness to agree with what I'm saying, then I suppose I've achieved nothing worth mentioning concerning the things we've been discussing. And I suppose you haven't either, if I don't testify on your side, though I'm just one person, and you disregard all these other people. (Gorgias $472 \mathrm{~b}-\mathrm{c})^{12}$

c. Socrates focuses exclusively on the statements, beliefs and commitments of his interlocutors, which is perhaps made most explicit in the following exchange with Protagoras:

[PROTAGORAS:] "It's not so absolutely clear a case to me, Socrates, as to make me grant that justice is pious, and piety just. It seems a distinction is in order here. But what's the difference? If you want, we'll let justice be pious and piety just."

[SOCRATES:] "Don't do that to me! It's not this 'if you want' or 'if you agree' business I want to test. It's you and me I want to put on the line, and I think the argument will be tested best if we take the 'if' out." (Protagoras 331c) $)^{13}$

However interested Socrates may be in discovering the truth, he clearly holds that it is of at least equally great importance that his interlocutor be honest and that he understands what they are inclined to think and believe.

d. Socrates himself avoids expressing personal opinions or advancing controversial theses. He tends, rather, to appeal to accepted truisms when he is not directly asking a question. Note, however, that this is not to say that Socrates does not occasionally express his own opinions and beliefs. As already mentioned, his dialogues partly (and inevitably) also serve as the examination of his own thinking. Nevertheless, it seems clear that it is his intention to avoid expressing his own opinion as much as he can. [p. 218]

e. Besides his notorious asking of question after question, it is noteworthy that Socrates constantly asks his interlocutors whether they can follow or whether they agree. Despite his infamous 'Socratic irony', Socrates is by no means a gnomic teacher.

f. Quite the contrary, Socrates exhibits an extreme eagerness to give more detailed expression to his points or re-express one of his points whenever his interlocutors do not agree or have difficulties understanding him. Thus, Socrates is not only eager to ensure that he fully understands his

12 See also Protagoras $359 \mathrm{c}-\mathrm{d}$.

13 See also Crito 49d. 
interlocutors, but equally pays attention to their understanding of him so as to ensure that they understand each other. This gets illustrated in numerous passages in which Socrates elaborates on a point or question prompted by the expressed or perceived lack of understanding of his words on the part of his interlocutor. ${ }^{14}$

g. Socrates himself also constantly asks for the meaning of what his interlocutors say in the course of a conversation. ${ }^{15}$

h. Socrates, as is more widely acknowledged, seeks to uncover incoherent presumptions and related difficulties on the part of his conversational partners. I have already hinted at one wonderful instance of this practice above with regard to the Euthyphro.

All of these practices illustrate the characteristic aspect of the Socratic method that consists in Socrates' special attention to his individual interlocutors (that is, as philosophising human beings rather than dummy opponents in yet another sophistic performance), which does not usually receive much attention. In the following, after briefly addressing an objection that is likely to be made at this early stage of the argument, I shall attempt to show that certain more or less similar practices can be said to feature in later Wittgenstein's conception of philosophy. [p. 219]

\section{Interlude: Reply to an objection}

At this point it might be objected, with no particular reference to any comparison with Wittgenstein yet, that the way I have presented Socrates, i.e. leaving out the overarching epistemological and metaphysical concerns he is standardly assumed to have, makes him into some sort of linguistic idealist; but that, even if he wasn't a strictly metaphysical Platonist, he was at least a sceptical one (as in early sceptical readings of Plato); that, at any rate, Socrates wasn't interested in words or what we say but in the world; or, that he was a philosopher with a driving interest in metaphysical ontology, and not some sort of misguided linguist. Hugh Benson, in his chapter on 'Socratic Method' in The

14 See, for example, Charmides 167c-d, 170a-d, 173a, 174c-d; Laches 185b, 190d-191e, 191e192c; Lysis 216c-d, 218d-e; Euthydemus 279d, 293d-e; Gorgias 447c-d, 461d-462a, 463e, 463e-465a, 466c-d, 491d-e.

15 See, for example, Euthyphro 13a-d; Charmides 173d-174a; Laches 195a, 195c, 195d, 196a-d; Lysis 208a, 212b; Protagoras 333d, 334a; Gorgias 450b-451a, 466a-b, 488b-d, 489d, 499d; Lesser Hippias 364c-d, 369d; Ion 540b-c, 540e-541a. 
Cambridge Companion to Socrates, for instance, writes the following: 'It is nearly certain that in pursuing his "What is piety?" question, for example, Socrates is not asking for the meaning of the word "piety" .... He is certainly not asking a question that could be answered by using a dictionary. He is asking the same sort of question that scientists ask when they ask "What is water?" and discover that the answer [sic] "Water is $\mathrm{H}_{2} \mathrm{O}$ ". ${ }^{16}$

Now, the main problem with this kind of objection, it appears to me, is this: it is wrongly presupposed, as so often in the related kind of argument against so-called 'linguistic philosophy', that it is easily distinguishable whether in any given instance in our philosophical enquiry we are interested in the word or in the world. But, as Stanley Cavell has put it so beautifully:

If you feel that finding out what something is must entail investigation of the world rather than of language, perhaps you are imagining a situation like finding out what somebody's name and address are, or what the contents of a will or a bottle are, or whether frogs eat butterflies. But now imagine that you are in your armchair reading a book of reminiscences and come across the word "umiak". You reach for your dictionary and look it up. Now what did you do? Find out what "umiak" means, or find out what an umiak is? But how could we have discovered something about the world by hunting in the dictionary? If this seems surprising, perhaps it is because we forget that we learn language and learn the world together, that they become elaborated and distorted together, and in the same places..$^{17,18}$ [p. 220]

I therefore also find myself in agreement with Cavell when he notes that, 'Euthyphro does not need to learn any new facts, yet he needs to learn something: you can say either that in the Euthyphro Socrates was finding out what "piety" means or finding out what piety is'. ${ }^{19}$

\section{Two aspects of Wittgenstein's conception of philosophy}

Contrary to a still common belief, Wittgenstein was no philosopher of language. Or, if he was, then he was equally a metaphysician. Like Socrates, he was not

16 Op. cit. note 9, 194.

17 Stanley Cavell, 'Must We Mean What We Say?', in op. cit. note 1, 19.

18 It may be of interest to also note that, for instance, in an attempt to explain Wittgenstein's 'antiPlatonism' Luigi Perissinotto commits the [p. 220] same mistake as Benson. The only difference is that Perissinotto tries to turn the fabricated dichotomy of word and world against Socrates (rather than Wittgenstein), riding on the cliché of Socrates the silly old essentialist. See Luigi Perissinotto, “'The Socratic Method!": Wittgenstein and Plato', in Wittgenstein and Plato, edited by Luigi Perissinotto and Begoña Ramón Cámara (London: Palgrave Macmillan, 2013).

19 Op. cit. note 17, 21. 
interested in either the word or the world, but rather in both. ${ }^{20}$ And, like Socrates, he had an acute sense for philosophical methodology, questions concerning the nature of philosophy itself. In what follows I am going to, firstly, describe one aspect of Wittgenstein's later methods that is significantly related to the concern about the philosophising individual that we have already noted to be a striking feature of the Socratic method in the preceding section. However, secondly, I am going to try to further indicate how the practice of the resulting kind of philosophy - despite its focus on the philosophising individual - can still be genuinely concerned with the truth with respect to a particular subject matter or question. [p. 221]

Wittgenstein, by now notoriously, often compares his (later) methods of philosophy to a kind of therapy, especially on occasion to psychotherapy and more specifically to Freud's psychoanalysis; e.g. in the following passage from The Big Typescript:

[in philosophy] we can only convict somebody else of a mistake if he acknowledges that this really is the expression of his thinking. For only if he acknowledges it as such, is it the correct expression. (Psychoanalysis.) What the other person acknowledges is the analogy I am proposing to him as the source of his thought. (BT 410) ${ }^{21}$

In recent years there has been increasing controversy about the extent to which this analogy holds or can even be helpful. ${ }^{22}$ As Anthony Kenny has also noted, for instance, emphasising the supposed therapeutic aspects of Wittgenstein's philosophy can easily produce the appearance of some sort of anti-philosophy, ${ }^{23}$ whose sole purpose is the negative one of ridding ourselves of misunderstandings that are engendered by some sort of linguistic

20 G. E. Moore's note in 'Wittgenstein's Lectures in 1930-33' (1954) remains true of Wittgenstein also in later years: '[Wittgenstein] did discuss at very great length ... certain very general questions about language; but he said, more than once, that he did not discuss these questions because he thought that language was the subject-matter of philosophy.... He discussed it only because he thought that particular philosophical errors or "troubles in our thought" were due to false analogies suggested by our actual use of expressions; and he emphasized that it was only necessary for him to discuss those points about language which, as he thought, led to these particular errors or "troubles" ('Wittgenstein's Lectures in 1930-33', Mind 63 (249) (1954), 5-6).

21 Cited after Ludwig Wittgenstein, The Big Typescript. TS 213 [1930s], edited and translated by C. G. Luckhardt and M. A. E. Aue (Oxford: Blackwell, 2005).

22 However, relevant secondary literature dates back as far as to authors such as Friedrich Waismann and John Wisdom. See, for example, Friedrich Waismann, 'How I See Philosophy' [1956], in How I See Philosophy, edited by Rom Harré (London: Macmillan, 1968) and John Wisdom, 'Philosophical Perplexity', Proceedings of the Aristotelian Society 37 (1936), 71-88.

23 The most striking recent example of this tendency is Alain Badiou's Wittgenstein's Antiphilosophy (London: Verso, 2011). See also Dale Jacquette, 'Later Wittgenstein's Anti-Philosophical Therapy', Philosophy 89 (2) (2014), 251-72. 
misconceptions: 'If philosophy is therapeutic ... then must not the role of philosophy be a negative one? Philosophy, it seems, is only useful to people who are sick in some way; a healthy person ... has no need of philosophy'. ${ }^{24}$ Kenny then goes on to point out that, even though philosophy's role (under this conception) is indeed a wholly negative one, it is still relevant for human beings per se, insofar as it is part of our human condition that we speak natural languages which have the same traps for everyone who engages in any sort of abstract or [p. 222] theoretical thinking. ${ }^{25}$ And while Kenny does mention a positive aspect of Wittgenstein's philosophy, the creation of 'Übersichten' (overviews, surveys) or 'übersichtliche Darstellungen' (perspicuous (re)presentations), he goes on to subordinate this aim under the negative aim of dissolving difficulties. ${ }^{26}$

I do not quite agree with this. Whatever Wittgenstein's own characterisation of (his) philosophy may have been at one point or another, I believe there is a clear and important case to be made for a genuinely positive effect of his philosophy. For example, besides certain methods and techniques (finding new analogies, drawing comparisons, inventing language-games, etc.) of 'grammatical enquiry' as well as associated skills (creativity, imagination, etc.), the teaching of methods by way of examples (PI §133) will also help us apart from peripheral factual knowledge that comes with it as a by-product - to better understand whatever the subject of our (exemplary) inquiries is, in ways that are truly philosophical insofar as they might be roughly circumscribed as 'knowing our way about with these things', viz. having successfully reversed the philosophically problematic state of 'I don't know my way about' (PI §123). ${ }^{27}$ As a look at some of Wittgenstein's manuscripts as well as his lectures reveals, apart from the form of teaching in the posthumously published Philosophical Investigations, the conception of philosophy taught in this manner also

24 Anthony Kenny, 'Wittgenstein on the Nature of Philosophy', in Wittgenstein and His Times, edited by Anthony Kenny and Brian McGuinness (Chicago: University of Chicago Press, 1982), 4-5.

25 See ibid., 17-19. Wittgenstein expresses a similar idea in CV 22 (Ludwig Wittgenstein, Vermischte Bemerkungen. Eine Auswahl aus dem Nachlaß / Culture and Value. A Selection from the Posthumous Remains [1914-51], edited by Georg Henrik von Wright in collaboration with Heikki Nyman, revised edition of the text by Alois Pichler, translated by Peter Winch (Oxford: Blackwell, 1977/1998)).

26 For the same kind of move cf. also P. F. Strawson, 'Construction and Analysis', in The Revolution in Philosophy, edited by A. J. Ayer, W. C. Kneale, G. A. Paul, D. F. Pears, P. F. Strawson, G. J. Warnock and R. A. Wollheim (New York: St Martin's Press, 1956).

27 PI = Philosophical Investigations, edited by G. E. M. Anscombe and Rush Rhees, revised fourth edition by P. M. S. Hacker and Joachim Schulte, translated by G. E. M. Anscombe, P. M. S. Hacker and J. Schulte (Oxford: Wiley-Blackwell, 1953/2009). 
provided space for more exploratory work, e.g. the space of psychological concepts.

It is helpful to see how in this regard Wittgenstein's conception of philosophy resembles that of Socrates. When we think about friendship, for instance, and perhaps at first get rather confused about what it could be, after some time we will hopefully - if we conduct our enquiries in the right way know better what it is (even though we [p. 223] might be more inclined than ever to say that we don't): ${ }^{28}$ it is only after having conducted such philosophical reflection on the question 'What is love?', say, that I will be able to give a halfway decent answer to my children when they ask me this question repeatedly.

Kenny mentions one more aspect of Wittgenstein's philosophy, or rather his conception of it, which seems to me to be true regardless of the aforementioned disagreement I may have with his interpretation and which is of great relevance to the argument of this essay. Kenny writes: 'Philosophy is something which everybody must do for himself; ... In the case of curing an individual sickness or in the case of mental discipline one cannot say that once done it need not be done again. It must be done for each person afresh'. ${ }^{29}$ Unfortunately, Kenny does not give any indication of why he thinks this is. Rather, he seems to understand this as being a matter of course. In the following, then, I shall try to make a little bit more apparent the significance and function of this central aspect of Wittgenstein's conception of philosophy, which may also be called the individuality of philosophical understanding. ${ }^{30}$ [p. 224]

28 Cf. the ironic end of the Lysis: '[SOCRATES:] "Now we've done it, Lysis and Menexenus-made fools of ourselves, I, an old man, and you as well. These people here will go away saying that we are friends of one another-for I count myself in with you - but what a friend is we have not yet been able to find out"' (Lysis 223b).

29 Op. cit. note $24,25$.

30 Dale Jacquette has recently argued against the consistence of this last mentioned aspect of Wittgenstein's methodology, hence rejecting the 'psychological' component and embracing the 'semantic' component instead, viz. that the real problems for Wittgenstein lay in our common language ('language itself') rather than the 'language-using subject' (see Jacquette, op. cit. note 23, $264 \mathrm{ff}$.). However, as I shall argue in the following, it is in fact essential not to let these two vital components come apart (as in Jacquette's account) in order to see the positive effects of this method that it has in both 'objective' and 'subjective' matters, viz. how Wittgenstein's (later) philosophy, pace Jacquette, is not some kind of 'anti-philosophy'. Cf., for example, the following reflection of Wittgenstein's in this connection: 'What is it that is repulsive in the idea that we study the use of a word, point to mistakes in the description of this use and so on? First and foremost one asks oneself: How could that be so important to us? It depends on whether what one calls a "wrong description" is a description that does not accord with established usage - or one which does not accord with the practice of the person giving the description. Only in the second case does a philosophical conflict arise' (RPP I §548 = Remarks on the Philosophy of Psychology. Vol. I [1945-47], edited by G. E. M. [p. 224] Anscombe and G. H. von Wright, translated by G. E. M. Anscombe (Oxford: Blackwell, 1980)). 


\section{Why don't we fall off the earth?}

Wittgenstein's declared aim (or at least one of them) was to 'show the fly the way out of the fly-bottle' (PI §309). But achieving this entails that the fly actually understands what we are trying to show it. Yet some flies aren't exactly smart and most others can be expected to be at least as hard a case as the recalcitrant student in PI $§ 185$. And what is a helpful hint for one fly might only create more confusion for another. I think that something similar is true of homo philosophandus. As Wittgenstein writes: 'Any explanation can be misunderstood' (PI §28). And I believe this holds true of philosophical matters in particular. The following story about Wittgenstein, as retold by Warren Goldfarb, might be apt to illustrate this:

Imagine a child, learning that the earth is round, asking why then people in Australia don't fall off. I suppose one natural response would be to start to explain about gravity. Wittgenstein, instead, [presumably being somewhere in Europe] would draw a circle with a stick figure atop it, turn it upside down, and say "Now $w e$ fall into space." 31

Wittgenstein addresses the child's question not as a mere call for information that the child was lacking, but as unclarity on the part of the child about certain pieces of information which they already possess. Thus, as was the case with Socrates and Euthyphro, Wittgenstein does not tell the child anything they did not know before but helps the child to a better understanding of (the implications of) what they already know, trying to offer a representation that will be perspicuous to the child. Goldfarb puts it thus:

[Wittgenstein] is examining the source of the child's question, in the concepts with which the child is operating. Given those concepts, an appeal to gravity can do nothing but mislead: the child will take it that the antipodal people are upside down, but they have gravity shoes, or glue, or something similar, that keeps them attached to the surface of the earth; as for us, we are right [p. 225] side up, so the problem does not arise. What Wittgenstein's trick does is precisely to expose the conceptual confusion in the way the child is thinking of up and down. ${ }^{32}$

31 Warren Goldfarb, 'Wittgenstein on Understanding', Midwest Studies in Philosophy 17 (1) (1992), 109-122, 111. Goldfarb takes the story from Georg Kreisel, 'Wittgenstein's Theory and Practice of Philosophy', British Journal for the Philosophy of Science 11 (43) (1960), 238-51. Cf. also Wittgenstein’s discussion in PI §351.

32 Op. cit. note 31 . 
While being interested primarily in explaining the difference between Wittgenstein's philosophical explanation and a standard scientific explanation, Goldfarb does not mention that, in principle, there is no reason why the child should not also misunderstand Wittgenstein's trick. The story, as it is told, seems to imply that the child did indeed actually stop asking the question because Wittgenstein successfully illustrated how their question was confused. However, it seems to me that this could only mean that Wittgenstein fortuitously (or perhaps in virtue of his wise experience) hit the right button and thus 'exposed the conceptual confusion', as Goldfarb has it, only somewhat luckily. For example, in a manner not too dissimilar from the recalcitrant student of PI $§ 185$ (while of course still much less of a lost case), the child could have pointed to the upper figure in the inverted drawing and replied, 'well, no; we don't fall into space now, because we're up there, stupid!'

Therefore, as a closer look at this little story brings out: one and the same expression - here in the form of the question 'Why don't people in Australia fall off the earth?'- can be the result of any number of misunderstandings. When dealing with this type of problem, as Wittgenstein remarked, we will only be able to make progress if 'the other person acknowledges ... the analogy I am proposing to him as the source of his thought' (BT 410). This is why for Wittgenstein, as for Socrates, it is so important to pay close attention to one's interlocutor, their words, their reactions and their responses. If one particular attempt to find the right analogy fails, this need not therefore be seen to pose a serious problem for our respective philosophical method. Like any of us, presumably, Wittgenstein would have had a number of alternative responses at his disposal. Of course, for example, he could have tried to bring out the point of the reversed picture by addressing the child with a series of questions, like Socrates would have done.

\section{An example}

Let us have a brief look at what may be regarded as a slightly more profound example. It can be argued that something similar, as in [p. 226] the case of the child and the earth, is true of Wittgenstein's (in)famous 'meaning is use'. 33 Namely, it can be argued that, whatever the insight Wittgenstein wanted to

33 The full quote of the passage that is commonly referred to as the source of this insight goes, of course, as follows: "For a large class of cases of the employment of the word "meaning" - though not for all - this word can be explained in this way: the meaning of a word is its use in the language' (PI §43). 
convey might be, it is something which, as Kenny put it, 'must be done for each person afresh' or with respect to which progress can only be made if one expression, which one might be inclined to give to it, happens to be the one which is understood correctly by someone (else) (and so on for all other possible expressions we could use). However, how little such progress has in fact been made with respect to this particular insight of (later) Wittgenstein's has already been noted by O. K. Bouwsma as early as 1961, and his observation appears to have lost none of its relevance:

The meaning of a word is its use.... Nearly everyone these days speaks and writes in this new fashion. And yet nothing has been changed. If before we were puzzled with: What is the meaning of a word? now we are puzzled with: What is the use of a word? ${ }^{34}$

The difficulty, therefore, is not merely, as it is often made to look, taking Wittgenstein to not be expounding a fully-fledged use-theory of meaning. ${ }^{35}$ Rather, the original difficulty of understanding Wittgenstein's point about meaning and use consists in seeing how, as with the story about the child and the earth, Wittgenstein here too employs a certain picture in an attempt to put a rather specific point, that is not at all easily made to any particular person, to anyone who might happen to pick up his book. Hence, the original difficulty for Wittgenstein to make his lesson understood, as the author of a philosophical book, can be seen to be what I proposed calling the individuality of philosophical understanding'. 36 Hence, the difficulty is fundamentally the same difficulty as the one he [p. 227] introduces in the early sections of the book, albeit with regard to much simpler cases:

Perhaps someone will say, "two" can be ostensively defined only in this way: "This number is called 'two'." For the word "number" here shows what place in language, in grammar, we assign to the word. But this means that the word "number" must be explained before that ostensive definition can be understood. (PI §29)

The sort of response which follows, I believe, holds (at least) as true of any philosophical explanation as of the "ostensive definition of "two"':

34 O. K. Bouwsma, 'The Blue Book', Journal of Philosophy 58 (6) (1961), 141-62, 158-9.

35 Notably, however, even Anthony Kenny ran into these problems; see Anthony Kenny, Wittgenstein, revised edition (Oxford: Blackwell, 1973/2006), chap. 9.

36 For an elaborated treatment of related questions concerning philosophical authorship see my 'The Morals of Writing Philosophy: Socrates, Plato, Wittgenstein', in Modernism and the Moral Life, edited by Ben Ware (Manchester: Manchester University Press, forthcoming). 
Whether the word "number" is necessary in an ostensive definition of "two" depends on whether without this word the other person takes the definition otherwise than I wish. And that will depend on the circumstances under which it is given, and on the person I give it to. (PI §29) ${ }^{37}$

Another way of seeing the resulting complexity of this example, 'meaning is use', consists in comparing Wittgenstein's countless other attempts of expressing what seems to be essentially the same point, e.g., most prominently perhaps, in section 1 of Philosophical Investigations. There, after introducing the famous language-game of the shopkeeper who manages to sell five red apples using a shopping list which says 'five red apples', Wittgenstein has this short dialogue follow:

"But how does he know where and how he is to look up the word 'red' and what he is to do with the word 'five'?" - Well, I assume that he acts as I have described. Explanations come to an end somewhere. - But what is the meaning of the word "five"? - No such thing was in question here, only how the word "five" is used. (PI §1)

Surely, Wittgenstein could have written: ‘don't ask this question'? Or, 'don't ask this question in a way as to suggest there must be more to the meaning of the word than its mere use in this language-game'? But it seems that apparently he could not have done [p. 228] so: any more direct warning, Wittgenstein appears to have thought, would likely have had the wrong effect in this case. In fact, considering the apparently most 'explicit' expression of this same point in PI $\S 43$ and the many wrong effects it actually had, 38 then: perhaps, it might be safe to say that, had Wittgenstein lived to witness the tragic story of this one remark, section 43 would have counted among the first to be cut out again from his manuscript even before publication.

Wittgenstein's awareness of the important variance in the understanding of different individuals with regard to the point expressed in, amongst many others, sections 1 and 43 - that is, in particular, his awareness of the two sides of the coin that is the difficulty of dispelling one kind of misunderstanding without engendering a new one - gets even more evident when we take a look at a related section such as $\S 138$ :

37 Conversely, then, the following can be said: "The definition of the number two, "That is called 'two"” - pointing to two nuts - is perfectly exact' (PI §28), as is in fact noted by Wittgenstein early on in the relevant passage. Thanks to Warren Goldfarb for reminding me of this important line.

38 See for instance the discussion of such wrong effects in James Conant, 'Wittgenstein on Meaning and Use', Philosophical Investigations 21 (3) (1998), 222-50. 
But can't the meaning of a word that I understand fit the sense of a sentence that I understand? Or the meaning of one word fit the meaning of another? - Of course, if the meaning is the use we make of the word, it makes no sense to speak of such fitting. But we understand the meaning of a word when we hear or say it; we grasp the meaning at a stroke, and what we grasp in this way is surely something different from the use which is extended in time! (PI §138)

This particular misunderstanding of what Wittgenstein is trying to teach us with respect to meaning and use - a lesson of which $\S 43$ is generally assumed to form a salient part - leads up to the entire discussion of rules and rulefollowing, which extends over the subsequent series of more than a hundred sections starting from $§ 139$ (and even further if we want to believe Saul Kripke’s interpretation). Wittgenstein must have thought that, hopefully, the thus emerging web of a manifold of interconnections would correct any such misunderstandings. However, as we know today, alas, it has not.

But (one might be inclined to ask), what is left then, in particular (or, in general?), of Wittgenstein's pointing out something about meaning and use? What is he doing with 'meaning' and 'use'? - O. K. Bouwsma, once more, has expressed this point with admirable sharpness, touching upon several of the themes discussed in the course of this essay so far: [p. 229]

It is intended... as an analogy... it comes to something like this: If you will say 'use' and write 'use' instead of 'meaning' in writing and speaking of words, and can manage to think accordingly, that will help. Help what? It will help you to rid yourself of the temptation to think of the meaning as something in the dark which you cannot see very well. The idea is that if your thinking is dominated in this case by one misleading analogy then you may be led right by another leading analogy. If, of course, that second analogy also misleads one, not much may be gained.... So we may understand that sentence as one which is intended to help us to a change in perspective. Once that change has come about, the sentence ... is of no further use. ${ }^{39}$

I believe more needs to be said, however. For, to some, this might sound all too negative again. One might also wonder, for example: if there are no doctrines to be learnt, are there only things to be unlearnt? - And, importantly, here the answer should be: No. But, just like with any Socratic dialogue, there is no one single determinate point to take home either. There are, amongst others, the following things to be learnt: a certain feeling (or taste?) for philosophical

39 Op. cit. note $34,159$. 
problems, a way of dealing with them, methods, techniques, ${ }^{40}$ a way of dealing with people, a way of understanding them, a way of understanding ourselves, and finally a way of seeing the world, a way of life. And we will surely not fail to learn more about language and whatever our favourite subjects are either. In the end, all these go together, hand in hand, word and world.

\section{Plato on the individuality of philosophical understanding}

In Plato's Phaedrus, Socrates discourses with his friend Phaedrus on the qualities of three kinds of communication: oratory/speech-giving, personal dialogue/conversation (dialectic) and writing. First, it should be noted that, throughout this particular dialogue, Socrates is concerned especially with a philosophical kind of understanding. He introduces this focus to Phaedrus, for example, in the following way: [p. 230]

SOCRATES: Now isn't this much absolutely clear: We are in accord with one another about some of the things we discourse about and in discord about others?

PHAEDRUS: I think I understand what you are saying; but, please, can you make it a little clearer?

SOCRATES: When someone utters the word 'iron' or 'silver,' don't we all think of the same thing?

PHAEDRUS: Certainly.

SOCRATES: But what happens when we say 'just' or 'good'? Doesn't each one of us go in a different direction? Don't we differ with one another and even with ourselves? (Phaedrus 263a) ${ }^{41}$

Secondly, it will be useful to notice how, like Wittgenstein, Plato compares 'the art of the true rhetorician', i.e. philosophy, with that of the medical doctor:

SOCRATES: Well, isn't the method of medicine in a way the same as the method of rhetoric?

PHAEDRUS: How so?

SOCRATES: In both cases we need to determine the nature of something-of the body in medicine, of the soul in rhetoric. Otherwise, all we'll have will be an empirical and artless practice. We won't be able to supply, on the basis of an art, a body with the medicines and diet that will make it healthy and strong,

40 These 'methods and techniques' should now also be seen to comprise the equivalents of the Socratic ones listed in section 2, in particular those listed under (b)-(g).

41 See also Phaedrus 261a and 278d. 
or a soul with the reasons and customary rules for conduct that will impart to it the convictions and virtues we want. (Phaedrus 270b) ${ }^{42}$

A medical doctor's efforts are usually directed at other people's health. Like philosophers, Plato implies, they get trained to understand others, which is a necessary element of both arts. The analogy with a kind of therapy, in its most general sense, emphasises the role of the individual in philosophical understanding. However, neither in Plato nor in Wittgenstein need this mean that all philosophical work is the mere exorcism of one sort of misunderstanding or another.

Then, again discussing the art of rhetoric while really expounding the ideal of philosophical conversation (dialectic), Plato has Socrates and Phaedrus agree on the following: [p. 231]

SOCRATES: Since the nature of speech is in fact to direct the soul, whoever intends to be a rhetorician must know how many kinds of soul there are. Their number is so-and-so many; each is of such-and-such a sort; hence some people have such-and-such a character and others have such-and-such. Those distinctions established, there are, in turn, so-and-so many kinds of speech, each of such-and-such a sort. People of such-and-such a character are easy to persuade by speeches of such-and-such a sort in connection with such-andsuch an issue for this particular reason, while people of such-and-such another sort are difficult to persuade for those particular reasons.

The orator must learn all this well, then put his theory into practice and develop the ability to discern each kind clearly as it occurs in the actions of real life. (Phaedrus 271d-e) ) $^{33}$

It seems to me that in the Phaedrus, we find Plato theorising about just what I presented in sections 1 and 2 of this essay as a much-neglected aspect of the Socratic method. In fact, all of the characteristics of Socrates' philosophical dialogues listed in section 2 can now be seen to flow from the same conviction expressed in the Phaedrus; namely the conviction that, in order to teach any philosophical insight to anyone, let alone philosophy as an art (as a method), it is essential to know whom you are teaching it to, to know your interlocutor's background knowledge, as well as their temptations and desires (or, in other words: their soul). This is what I earlier proposed to call the individuality of philosophical understanding', which as we saw in previous sections plays an important role also in Wittgenstein's conception of philosophy.

42 See also Phaedrus 268a-269d.

43 See also Phaedrus $277 \mathrm{~b}-\mathrm{c}$. 
Considering the inclusive presentation of oratory and dialectic (philosophy) in the Phaedrus, the question may reasonably occur of why this is in any way unique to philosophy and not, rather, true of almost any act of communication. In other words, it could be objected that Socrates (in the Phaedrus) would actually say the same thing about any spoken discourse, that it is no special characteristic of philosophy that one must know one's interlocutor's soul, and that I am reading something into the text that isn't really there. But let us consider the following. I said that Socrates chooses to introduce his focus on philosophical understanding by pointing to those notions about whose nature we are most likely to disagree, 'with one another and even with ourselves'. Why is that? I think that Socrates chooses to do so [p. 232] because for him, this is the touchstone of a philosophical subject: insofar as the philosopher in us wants to know more or better in cases where we would normally take ourselves to know enough already (at least tacitly), it is fundamental for any serious philosophical dialogue that there be (or that room be made for) disagreement between the dialogue partners (even though this 'disagreement' might at any moment turn out to be a disagreement about the meaning of the words that are used by the dialogue partners and indeed typically, although in no way necessarily, does turn out to be just that, viz. a misunderstanding of what one of the dialogue partners was trying to say). This is different from science, say, where our interest is driven by ignorance (the opposite of 'knowledge') rather than disagreement or misunderstanding (the opposite of 'understanding'). Philosophical matters are those where opinions commonly lie further from each other than in any other kind of human endeavour. Is there any philosophical question where both the position that the thing in question exists and the position that it does not exist haven't been defended in all seriousness? From a historical perspective, philosophical questions can be said to be the ones with regard to which 'experts' have tended to disagree for decades, sometimes hundreds or even thousands of years. Almost no philosophical question can be said to have been answered once and for all (unless we stipulate an extremely narrow notion of 'philosophical question'). The point to be made (following Plato's Phaedrus), therefore, with respect to the relative significance of knowing one's interlocutor in philosophy, as compared to just any act of communication, is that no other kind of discourse has more potential for disagreement and hence misunderstanding between its respective participants - which is why it is in philosophy that it is most important to know one's interlocutor's soul well and hence to seek, and pay attention to, understanding each other. 


\section{An exemplar}

It has often been said that in Plato's Socratic dialogues we do not find Socrates reflecting on his own methods. ${ }^{44}$ And with respect to what has come to be thought of, standardly, as the Socratic method, viz. the elenchus, this is certainly true. Socrates does indeed never use the word 'elenchus', nor does he describe this technique anywhere. ${ }^{45}$ [p. 233] Plato's Laches, however, introduces many of those typical practices of the Socratic art of philosophising which I have described in this essay. In this dialogue, Socrates is shown discussing 'courage (andreia)' with the two accomplished generals Nicias and Laches, who have been asked to teach this virtue to the sons of two of their friends. The two generals soon find that they do not seem to have quite such a clear understanding of what courage is as, both being experienced military men, they had assumed they did. And it forms a unique moment in Plato's Socratic dialogues when Socrates attempts to begin his examination and Laches does not understand what it is that Socrates is asking from him when posing his infamous 'What is the F?' question. At first Laches intuitively presents Socrates with a paradigmatic example of courage, rather than an answer in the form of a general definition. And surely, this is what many of us would do most naturally, and there is absolutely nothing wrong with that in principle. Socrates then spends considerable time explaining to Laches what form the latter's answer should take and how Socrates intends his question. It is remarkable how, from this point in the dialogue onwards, Socrates, now knowing about Laches' unfamiliarity with this kind of philosophical discourse, continues to instruct him and Nicias in how to conduct a philosophical conversation with one another. And, notably, in the great majority of cases of his instruction, Socrates urges Nicias and Laches to try to understand what the other is attempting to say, rather than - as has been much more common in philosophical discourse until today - simply dismissing the other's words as nonsense or arguing against a distorted version of the other's expressed view. Take as an example the following passage in which Nicias offers his definition of courage:

SOCRATES: Let him state what kind of knowledge it is.

NICIAS: What I say, Laches, is that it is the knowledge of the fearful and the hopeful in war and in every other situation.

\footnotetext{
44 See, for instance, Gregory Vlastos, op. cit. note $3,1$.

45 As I have argued above, the elenchus is better understood as merely one prominent technique of his.
} 
LACHES: How strangely he talks, Socrates.

SOCRATES: What do you have in mind when you say this, Laches?

LACHES: What do I have in mind? Why, I take wisdom to be quite a different thing from courage.

SOCRATES: Well, Nicias, at any rate, says it isn't.

LACHES: He certainly does-that's the nonsense he talks. [p. 234]

SOCRATES: Well, let's instruct him instead of making fun of him. (Laches 194e-195a)

By 'instruct' Socrates here clearly means, not 'teaching what courage really is', but rather 'helping someone express themselves more clearly, in a way that will be more readily intelligible to us, by putting in front of them the problems we have in understanding what they say'. Compare also, for a second example, the first exchange between Laches and Nicias:

LACHES: It isn't clear to me from this, Socrates, what he is trying to say. Because he doesn't select either the seer or the doctor or anyone else as the man he calls courageous, unless some god is the person he means. Nicias appears to me unwilling to make a gentlemanly admission that he is talking nonsense, but he twists this way and that in an attempt to cover up his difficulty. Even you and I could have executed a similar twist just now if we had wanted to avoid the appearance of contradicting ourselves. If we were making speeches in a court of law, there might be some point in doing this, but as things are, why should anyone adorn himself senselessly with empty words in a gathering like this?

SOCRATES: I see no reason why he should, Laches. But let us see if Nicias thinks he is saying something and is not just talking for the sake of talking. Let us find out from him more clearly what it is he means, and if he is really saying something, we will agree with him, but if not, we will instruct him. (Laches 196a-c)

Equally there are a significant number of passages in which, although Socrates is not explicitly giving advice, one of the three men who are participating in the conversation expresses unclarity about what has been said by another or directly asks for the meaning of their interlocutor's words. In fact, most of the dialogue is framed as a quest for understanding what the other is trying to say that courage is. First Laches (190d-194b), and then Nicias (194c-199e) attempt to say what they respectively think it is. And - as we saw was the case with the Euthyphro in section 1 - it would be careless to say that the Laches ended, 'as usual', in aporia. For, more importantly, the dialogue ends at a point where Nicias finally feels understood by Laches and Socrates (see esp. 198b- 
199a). Hence, as in the case of the Euthyphro, in the case of the Laches too there seems to be available an understanding of the dialogue's ending which is not only less generic than the standard 'aporia' hypothesis (and hence more sympathetic to Plato as an author) but actually helps explain one of the more abstract themes of this dialogue, viz. the way it might have [p. 235] been intended as an exemplar of 'how to teach virtues (or, philosophy)'. ${ }^{46}$

Hence, that which Plato has Socrates say in the above-quoted passage from the Phaedrus gets demonstrated, as an example, in (or, better: by) the Laches: namely, the fundamental importance for philosophical dialogue - and hence, understanding - that each dialogue partner sincerely aspires to understand the other, what they mean by their words, their respective ways of thinking and understanding, etc. so that, as a speaker, they can put their points in a way that ensures the best understanding on the part of their listener, and, as a listener, they can present their questions in a way that ensures the best understanding on the part of the speaker.

\section{Philosophical understanding}

Having said this, it should then - once more - be noted how in a Socratic dialogue it is usually at least three, and not just two, things that go hand in hand. That the conversational partners understand one another is (in most cases) only a necessary condition for a successful understanding of a philosophical kind, albeit, as I have argued in this essay, a very significant one. Besides the minimum number of two participants - 'the subjects' of the conversation - who each usually play the roles of both the speaker and the listener, there is 'the object' of the conversation (i.e. that which we would more colloquially call its 'subject'). This is where the analogy between philosophy and (most kinds of) therapy ends - unless we imagine two doctors examining each other for the sake of learning about a certain illness or organ. Philosophy (Socratic philosophy, anyway), despite its emphasis on mutual understanding between its practising subjects, is, of course, not exclusively an attempt to understand someone else, their feelings and opinions. But it is directed - in principle, approximately as much as at the other and ourselves - at the truth of things.

46 On this latter point see also John M. Cooper, 'Socrates and Philosophy as a Way of Life', in Maieusis: Essays in Ancient Philosophy in Honour of Myles Burnyeat, edited by Dominic Scott (Oxford: Oxford University Press, 2007), 24 and Gregory Vlastos, op. cit. note 3, 6-7. 
This means, as I have stressed before, that it is important to appreciate the twofold function that is fulfilled by mutual understanding in philosophical discourse. Insofar as coming to understand (one) another brings about, hopefully (that is, if we don't find in the end [p. 236] that we meant the same thing all along), ${ }^{47}$ the acknowledgment of alternative perspectives on the world that were previously unknown to us, it brings about a new and philosophically different world (or a world with new things in it that we did not know before). In the most astonishing instances, it often means coming to see something most familiar to us - something 'that we know too well' and that is thus almost invisible to us - as though with a pair of new, different eyes: seeing connections we did not see before, making new, happy associations or appreciating differences where before everything used to appear as the same monotonous thing to us.

In the Laches, the twofold function of mutual understanding in philosophical discourse can be seen from the fact that, although the three men do not come very far in their understanding of the immediate object of their conversation ('courage') - and this is of course partly due to the considerable efforts they spend on reaching an understanding of each other - they nevertheless do also get somewhere in this respect; they can be said to have reached (the start of) a better understanding of what courage is. In fact, Plato makes this double function explicit in Nicias' expressed anticipation before the actual examination starts. For not only does Nicias there mention the subjective examination of oneself and one's beliefs, prejudices, etc. and those of one's interlocutors, which the method involves, but equally, towards the end, the objective kind of learning that it involves, concerning one's life and the world:

NICIAS: You don't appear to me to know that whoever comes into close contact with Socrates and associates with him in conversation must necessarily, even if he began by conversing about something quite different in the first place, keep on being led about by the man's arguments until he submits to answering questions about himself concerning both his present manner of life and the life he has lived hitherto. And when he does submit to this questioning, you don't realize that Socrates will not let him go before he has well and truly tested every last detail. ... I think that a man who does not run away from such treatment but is willing, according to the saying of Solon, to value learning as long as he lives, not supposing that old age brings him

\footnotetext{
47 This, it should be said, is itself a beautiful moment.
} 
wisdom of itself, will necessarily pay more attention to the rest of his life.

(Laches 187e-188b)

In the Phaedrus, the interplay in philosophical understanding between mutual understanding on the one hand and understanding of the world on the other is clearly marked by Plato's [p. 237] having Socrates not only remark on the importance of the former ('you must understand the nature of the soul' (277b)), but equally on the importance of the latter ('you must know the truth concerning everything' (277b)), in order to reach genuine philosophical understanding.

\section{Conclusion: Socratic dialectic and 'analytic' philosophising}

But there is one more - perhaps, at this particular point in time, also more apparently relevant - way in which Plato's Phaedrus brings out the twofold function of understanding each other in philosophy, which I want to mention before ending. In the Phaedrus, Plato has Socrates theorise about one of his most famous (or infamous) practices: 'the ("unsuccessful") search for essences'. 48 As everyone knows, Socrates typically proceeds by (eliciting) attempts to formulate what something is in the form of a general definition, which, once formulated, he goes on to criticise and dismiss. Commentators like to point out that Socrates' alleged ignorance, whether ironical or not, and also his 'knowing that he does not know anything', are illustrated by this practice. Now, in the Phaedrus, Plato has Socrates describe these two moments, i.e. the formulation of a definition and its subsequent criticism, in the following way:

SOCRATES: The first consists in seeing together things that are scattered about everywhere and collecting them into one kind, so that by defining each thing we can make clear the subject of any instruction we wish to give. Just so with our discussion of love: Whether its definition was or was not correct, at least it allowed the speech to proceed clearly and consistently with itself.

PHAEDRUS: And what is the other thing you are talking about, Socrates?

SOCRATES: This, in turn, is to be able to cut up each kind according to its species along its natural joints, and to try not to splinter any part, as a bad butcher might do. In just this way, our two speeches [about love] placed all mental derangements into one common kind. Then, just as each single body has parts that naturally [p. 238] come in pairs of the same name (one of them being called the right-hand and the other the left-hand one), so the speeches,

48 Wittgensteinians, in particular, tend to think of this practice in the pejorative mode; for instance, it is frequently contrasted with Wittgenstein's ideas about 'family resemblance'. Such a polemic attitude, however, as I have argued in this essay, is what really should be shunned in philosophy. 
having considered unsoundness of mind to be by nature one single kind within us, proceeded to cut it up-the first speech cut its left-hand part, and continued to cut until it discovered among these parts a sort of love that can be called 'left-handed,' which it correctly denounced; the second speech, in turn, led us to the right-hand part of madness; discovered a love that shares its name with the other but is actually divine; set it out before us, and praised it as the cause of our greatest goods.

PHAEDRUS: You are absolutely right.

SOCRATES: Well, Phaedrus, I am myself a lover of these divisions and collections, so that I may be able to think and to speak; ... God knows whether this is the right name for those who can do this correctly or not, but so far I have always called them 'dialecticians'. (Laches 265d-266c) ${ }^{49}$

Socrates' (elicitations of) attempts to define something can thus be understood as a purely heuristic method. Contrary to a common picture, Socrates need not actually be committed to believing that such essences can ever be formulated. Rather, from what we have seen in the preceding discussion, it appears that he uses this device primarily so that his interlocutors respond in the way he wishes them to and in order to lay a foundation for mutual understanding between the respective conversational partners by way of agreement as to the meaning of central terms of their subsequent discourse. However, again, it would be wrong to think that on such an interpretation Socrates (or Plato) turned out to be some sort of sceptic or nominalist. ${ }^{50}$ For, as Socrates points out, the criticism of formulated definitions, which follows every definition, is what really enables us to approach the thing we are interested in as it is ('along its natural joints').

The Socratic use of definitions, thus understood, is not only much less naïvely (or, metaphysically) realistic than usually portrayed, but actually quite close to the way analytic philosophers have always wanted to work. If anything, this, it seems to me, would be the [p. 239] right spirit in which to conduct a 'method of cases'. And arguably Wittgenstein's later method of language-games, understood as the stipulation of (and subsequent reflection on) objects of comparison (centres of variation) which 'through similarities and dissimilarities' (PI §130) are meant to throw light on the respective objects of our philosophical investigation, bears a strikingly close resemblance to this

49 Commentators, wrongly, have often not believed the Phaedrus' Socrates when he says that he himself is a 'lover of these divisions', but tend to ascribe the 'method of divisions' exclusively to the mature Plato instead (esp. in the Sophist and Statesman).

50 Note that in denying this I do not mean to argue in favour of a '(strongly) realist' interpretation of Plato or Socrates either. 
Socratic technique. However, the key to appreciating these similarities between the methods of Socrates, Plato, Wittgenstein and whatever we ourselves may aspire in philosophy lies in the acknowledgement of the oft-neglected role which the mutual understanding between the participants of a philosophical conversation plays in (the more general kind of) philosophical understanding of the world. ${ }^{51}$

51 Earlier versions of the material published here have been presented over the past two years at events in Bergen, Cambridge, Canterbury, Helsinki, Kiev, Kirchberg, London, Madrid, Manchester and Oxford. I would like to thank both the participants and the organisers of these events for many useful discussions. Special thanks go to Joel Backström, Bill Child, Jim Conant, Stefan Giesewetter, Andrew Godfrey, Jen Hornsby, Oskari Kuusela, Hannes Nykänen, Alois Pichler, Marie Rowe (a.k.a. McGinn) and Severin Schroeder. 